\title{
Production of ethylic biodiesel from Tilápia visceral oil
}

\author{
Oliveira L. E. ${ }^{1}$, Barboza J. C. S. ${ }^{2}$, Da Silva M. L. C. P. ${ }^{3}$ \\ 1,2,3 Department of Chemical Engineering \\ EEL-USP, University of Sao Paulo \\ Campus I - Lorena, 12600 São Paulo (Brazil)
}

Phone/Fax number:+0551231595169, e-mail: levi@dequi.eel.usp.br, mlcaetano@dequi.eel.usp.br

\begin{abstract}
The use of biodiesel from Tilapia visceral oil will allow the development of economy where a fishery is developed. The fishing industry has resulted in the production of large quantities of fish waste, especially fish viscera which are discarded into the environment. The aim of this work is to show the process of Tilapia visceral oil extraction, characterization and obtainment of biodiesel by ethylic route. For the feasibility of transesterification is necessary that the oil has low moisture content and free fatty acids (FFA) below 5\%, since the high value of these two parameters can preclude transesterification by forming high quantities of soap. The results of this study show that the Tilapia visceral oil has low moisture $(0,12 \%)$ and only $3.11 \%$ of FFA. For the experiment it was used $1.8 \%$ of catalyst $\mathrm{KOH}$, obtaining a high yield of biodiesel as shown by nuclear proton ${ }^{1} \mathrm{H}$ NMR analysis. The results are very promising and show that it's possible to convert a fish waste in biodiesel.
\end{abstract}

\section{Key words}

Tilapia visceral oil, oil characterization, ethylic biodiesel, FFA, moisture.

\section{Introduction}

Biodiesel is made from renewable sources such as vegetable oils and animal fats in order to replace diesel. This biofuel is biodegradable and non-toxic profile and has low emissions compared to petroleum diesel. The use of biodiesel will allow the development of agriculture, economy and environment, since its production chain begins on the field and ends in the industry $[1,2]$.

Among the raw materials for the production of biodiesel, the beef tallow is a great option. In Brazil, approximately $10 \%$ of the biodiesel produced is from this material that would be discarded. Another source of animal lipid, which should be explored, is the visceral fish oil. The Nile Tilapia (Oreochromis niloticus) is one of the most important fish grown in fish farms. It has some advantages, growing quickly and is resistant to poor water quality and disease. Hardiness and its adaptability to a wide range of culture system led to the marketing and production of tilapia in more than 100 countries.

In the scenario of global aquaculture, the production of Nile tilapia in 2007 was more than 2.1 million tons Global aquaculture production of Nile tilapia, in 2007, was over than 2.1 million tons. China is the largest producer of Nile tilapia, followed by Egypt, the Philippines and Thailand [3].

The growth of the fishing industry has resulted in the production of large quantities of fish waste, especially fish viscera which are discarded into the environment. Viscera represent from $7.5 \%$ to $15 \%$ of fish body weight and has no commercial value. The production of fish oil was 627,000 tonnes in 2007 , mostly produced from marine fish viscera [3].

The production and availability of fish oil is growing, but the market for fish oil has not grown at the same rate as it is most widely used by the pharmaceutical and food industry as a source of omega-3, which represents $20 \% 30 \%$ of the fatty acids present in fish oil. Excess production of fish oil and waste from the pharmaceutical and food industry and be used as a source for production of biodiesel.

For transesterification reactions, vegetable oil or fat should not contain more than $1 \%$ free fatty acids (FFA) [4,5]. If the level of FFA exceeds this threshold, the saponification reaction occurs preventing the separation of the ester from glycerin, and thereby reducing the yield rate of the transesterification reaction.

The esterification reaction between FFA and methanol, producing FAEE (fatty acid ethyl ester), can be represented in the following schematic form:

$$
\begin{gathered}
\stackrel{\mathrm{O}}{\|} \\
\mathrm{HO}-\mathrm{C}-\mathrm{R} \\
\text { FFA }
\end{gathered}
$$

Moisture is another factor that strongly influences the performance of the biodiesel production process. Both water and FFA readily react with the catalyst to form soaps which the tensile properties do not allow efficient separation of pure glycerol in the final step of the process.

The aim of this work is the extraction and characterization of Tilapia visceral oil analyzing moisture and FFA to choose the best procedure for the ransesterification reaction. Furthermore, it will be analysed the yield of transesterification reaction by proton ${ }^{1} \mathrm{H}$ RMN. 


\section{Material and method}

\subsection{Method of oil extraction}

The Tilapia fish were kindly supplied by Santo Antonio fishery in the municipality of Jacareí, State of São Paulo. The total weight was $2.365 \mathrm{~kg}$ fish, removing $220 \mathrm{~g}$ of viscera, obtaining therefore $9.3 \%$ of the visceral mass.

The first step was to cut the viscera still frozen into small pieces and put them into in $550 \mathrm{~mL}$ of boiling water for 20 minutes heating. Cooled down for 40 minutes and filtered in a strainer with fast flow rate (Figure 1).

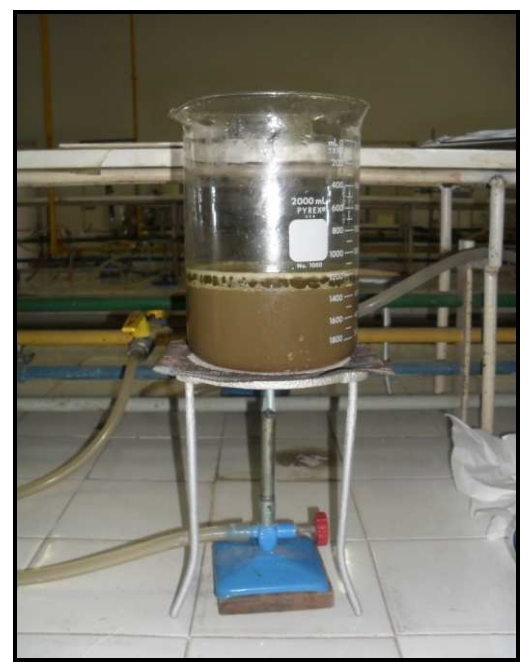

Fig. 1. Boiling the Tilapia viscera.

It was repeated the same operation and after separated from water, filtered again on a finer sieve and brought to the fire, now for 30 minutes. Cooled down for 40 minutes and filtered again in a fine sieve. Was repeated the same operation before and after the material is placed (Figure 3) in a separating funnel to separate the oil from the waste water (Figure 2).

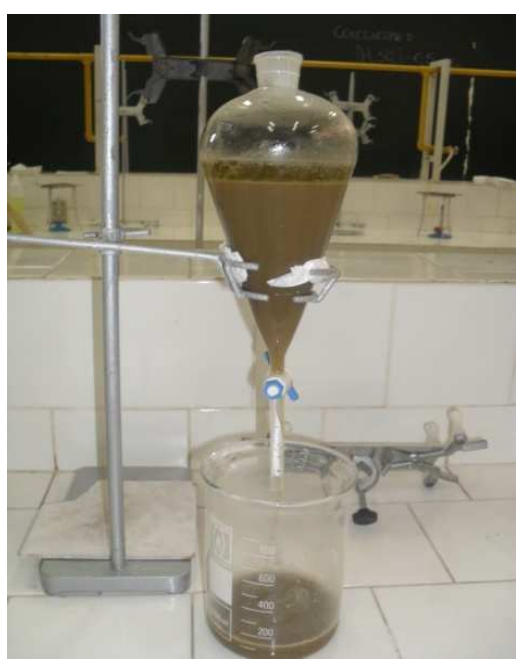

Fig. 2. Oil separation.

\subsection{Physico-chemical characterization of Tilapia visceral oil}

Characterization was carried out for Tilapia visceral oil regarding iodine $\left(\mathrm{gI}_{2} / 100 \mathrm{~g}\right)$, saponification $(\mathrm{KOH} \mathrm{mg})$, peroxide $(\mathrm{mEq} / \mathrm{Kg})$, acidity ( $\mathrm{mg} \mathrm{KOH} / \mathrm{g}$ ) and moisture content. The viability of the transesterification of oils is dictated by the content of free fatty acid (FFA) and moisture content. After determined the acidity, the FFA was calculated by the following formula:

$\%$ FFA $=\frac{\left(\mathrm{V}_{\text {sample }}-\mathrm{V}_{\text {blank }}\right) \times \mathrm{MM}_{\text {fatty acid }} \times \mathrm{C}_{\text {base }} \times 100}{\mathrm{~m}_{\text {sample }}}$

Where:

$\mathbf{V}_{\text {sample }}=$ Volume of $\mathrm{KOH}$ solution spent in the sample titration $(\mathrm{mL})$

$\mathbf{V}_{\text {branco }}=$ Volume of $\mathrm{KOH}$ solution spent in the blank titration $(\mathrm{mL})$

$\mathbf{M M}_{\text {base }}=$ Molar mass of $\mathrm{KOH}\left(56.1 \mathrm{~g} \mathrm{~mol}^{-1}\right)$

$\mathbf{C}_{\text {base }}=$ molar concentration of $\mathrm{KOH}$ solution $\left(\mathrm{mol} \mathrm{L}^{-1}\right)$

$\mathbf{M M}_{\text {fatty acid }}=$ Molar mass of oleic acid $\left(282 \mathrm{~g} \mathrm{~mol}^{-1}\right)$

$\mathbf{m}_{\text {sample }}=$ Weight of sample $(\mathrm{g})$

The moisture content was obtained by the Karl Fischer Tritator DL18 Mettler.

\subsection{Ethylic Biodiesel production}

For the transesterification reaction by ethyl route it will be used a temperature of $60^{\circ} \mathrm{C}$ for 90 minutes. For catalyst is used potassium hydroxide $(\mathrm{KOH})$ with the mass of $1 \%$ weight of Tilapia visceral oil.

The biodiesel from Tilapia visceral oil was obtained by chemical route using the catalyst potassium hydroxide $(\mathrm{KOH})$. The yield of ethylic biodiesel was obtained by proton NMR $\left({ }^{1} \mathrm{H}\right.$ NMR). The ${ }^{1} \mathrm{H}$ NMR consists in determining the signals emitted by the nucleus of the carbon atoms through interactions with magnetic fields and radio frequency energy induced. This is one of the techniques used for absolute determination of organic compounds.

\section{Results and discussion}

\subsection{Physico-chemical characterization of Tilapia visceral oil}

The results indexes of acidity, peroxide, iodine and saponification, the FFA and moisture content of the Tilapia viscera oil are shown in Table I.

Table I. - Characterization of Tilapia visceral oil.

\begin{tabular}{|c|c|}
\hline Properties & Oil \\
\hline Acidity index $(\mathrm{mg} \mathrm{KOH} / \mathrm{g})$ & 5.8 \\
\hline Peroxide index $(\mathrm{mEq} / \mathrm{Kg})$ & 23.0 \\
\hline Iodine index $\left(\mathrm{gI}_{2} / 100 \mathrm{~g}\right)$ & 72.35 \\
\hline Saponification index $(\mathrm{mg} \mathrm{KOH})$ & 177.8 \\
\hline Moisture $(\%)$ & 0.12 \\
\hline FFA \% & 3.11 \\
\hline
\end{tabular}


The result obtained for the level of FFA is satisfactory with a value of $3.11 \%$. Under $5 \%$ of FFA, the reaction can also be done with an alkaline catalyst, but additional catalyst should be added to compensate the lost catalyst in the formation of soap [6]. The soap created during the reaction is removed either with glycerol or washed out during the water wash. When the level of FFA is higher than 5\%, the soap inhibits separation of the methyl or ethyl esters and glycerol and contributes to emulsion formation during washing with water.

\subsection{Obtaining biodiesel from Tilapia visceral oil}

For the transesterification reaction it was used 1:9 molar ratio (Tilapia visceral oil: ethanol). To calculate the molar mass of oil, it was used the major fatty acid of the Tilapia visceral oil as described in the literature (Table II).

Table II. - Fatty acid composition of Tilapia visceral oil $[6]$.

\begin{tabular}{|l|c|}
\hline \multicolumn{2}{|c|}{ Fatty acid (\%) } \\
\hline Eicosapentaenoic (20:5) & 18.1 \\
\hline Palmitic (C16: 0) & 15.9 \\
\hline Docosahexaenoic acid (22:6) & 15.8 \\
\hline Oleic (C18: 1$)$ & 12.1 \\
\hline
\end{tabular}

It is known that eicosapentaenoic acid (C20:5) is the major fatty acid and was used in the following formula to find the average molar mass of the oil:

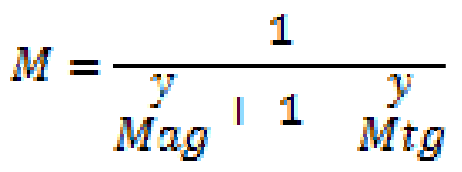

Where:

$\mathbf{M}=$ Molar mass average oil (g mol-1)

$\mathbf{M}_{\mathrm{ag}}=$ Molar mass of majority fatty acid $\left(\mathrm{g} \mathrm{mol}^{-1}\right)$ $\mathrm{mol}^{-1}$ )

$\mathbf{M}_{\mathrm{tg}}=$ Molar mass of major triglyceride fatty acid ( $\mathrm{g}$

$\mathbf{Y}=$ Acidity index $\left(\mathrm{mg} \mathrm{KOH} \mathrm{g}^{-1}\right)$.

It was found $929.36 \mathrm{~g} \mathrm{~mol}^{-1}$ for molar mass average of Tilapia visceral oil. Using $80 \mathrm{~g}$ of oil it was possible to calculate the amount of ethanol to be used in the transesrification (1:9).

First it was used $1 \%$ (oil weight) of $\mathrm{KOH}$ catalyst to obtain the ethyl biodiesel. But it was not visually detected the two phase separation formed of biodiesel and glycerol. The transesterification didn't occur as desired. It was necessary to repeat the experiment. Then, for $80 \mathrm{~g}$ of oil, rather than using $0.8 \mathrm{~g}$ of potassium hydroxide $(\mathrm{KOH})$, it was used $1.5 \mathrm{~g}$ of this catalyst. That is, instead of using $1 \%$ of $\mathrm{KOH}$, it was used approximately $1.8 \%$ of excess catalyst since the amount of FFA $=3.11$ is relatively high. With this amount of catalyst the transesterification occurred in high yield as discussed in Section 3.3.

\subsection{Yield of transesterification reaction}

By ${ }^{1} \mathrm{H}$ NMR analysis it can be seen that in the region between 3.5 and 4.5 shows several peaks characteristic signals of lipid material (Figure 3 ).

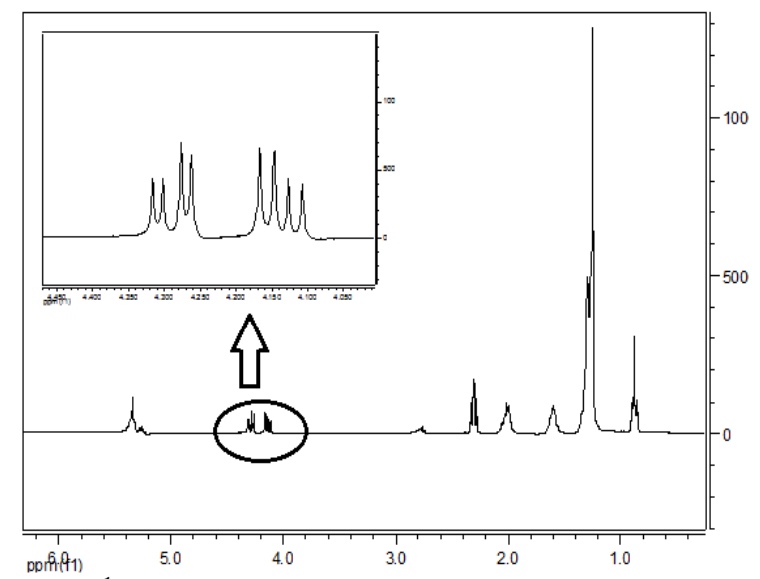

Fig. 3. ${ }^{1} \mathrm{H}$ NMR spectrum of Tilapia visceral oil.

In the ethyl ester spectrum it is possible to observe which corresponds $\mathrm{CH}_{2}$ quartet ethyl radical, indicating the transesterification reaction (Figure 4). Moreover, the peaks that are shown in the spectrum of the oil in the range of 4.1 to 4.3 , disappear in the spectrum of ethyl biodiesel, thus showing the high yield transesterification reaction.

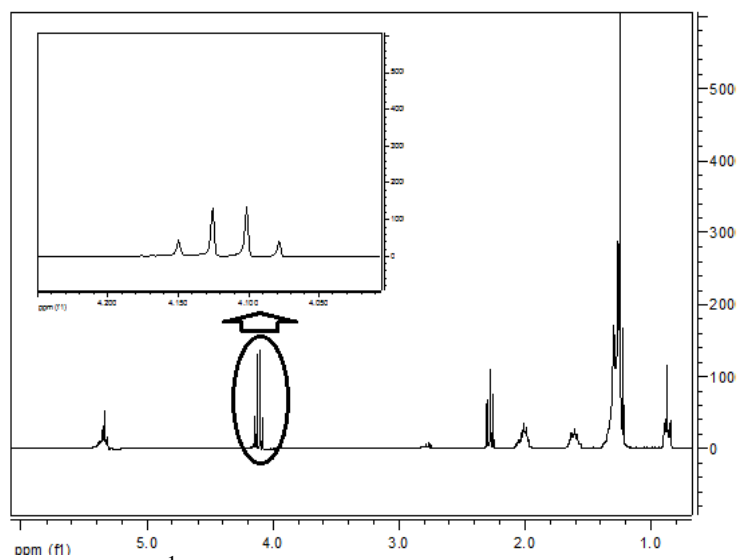

Fig. 4. ${ }^{1} \mathrm{H}$ NMR spectrum of ethyl biodiesel.

The other signals are matched in the two spectra, since they represent parts that do not suffer the transesterification reaction. It can be stated that the conversion was quantitative for this biodiesel, having a high yield.

\section{Conclusion}

The Tilapia visceral oil extraction is a simple process and does not require use of any type of solvent, being cheap and environmentally friendly. The characterization of the oil was important as it has detected a low moisture and acidity index, hence does not need any pretreatment. The transesterification reaction produced a high yield of biodiesel of Tilapia visceral oil. 


\section{Acknowledgement}

I would like to thank the Cnpq (Conselho Nacional de Desenvolvimento Cíentifico e Tecnológico) for the financial support.

\section{References}

[1] Darnoko D, Cheryan M. Kinetics of palm oil transesterification in a batch reactor. J Am Oil Chem Soc 2000;77:1263-7.

[2] Muniyappa PR, Brammer SC, Noureddini H. Improved conversion of plant oils and animal fats into biodiesel and co-product. Biores Technol 1996;56:19-24.

[3] Santos LD, Furuya WM, Matsushita M, Silva LCR, Silva TSDC, Botaro D.Conjugated linoleic acid (CLA) in Nile tilapia diets: productive performance, chemical and fatty acids composition. Rev Bras Zootec 2007;36:1481-8.

[4] Freedman B, Pryde EH, Mounts TL. Variables affecting the yields of fatty esters from transesterified vegetable oils. J Am Oil Chem Soc 1984;61:1638-43.

[5] Liu KS. Preparation of fatty acid methyl esters for gaschromatographic analysis of lipids in biological materials. J Am Oil Chem Soc 1994;71:1179-87.

[6] Santos F, Malveira J, Cruz M, Fernandes F. Production of biodiesel by ultrasound assisted esterification of Oreochromis niloticus oil. ScienceDirect, 275, 2009. 